\title{
INTELLECTUAL PROPERTY RIGHTS FOR DIGITAL LIBRARY AND HYPERTEXT PUBLISHING SYSTEMS*
}

\author{
Pamela Samuelson** \\ Robert J. Glushko***
}

\section{INTRODUCTION}

Computers and the concomitant capability they have provided for making copyrighted works available in digital form in networked environments have created many new kinds of expressive opportunities. Computer technology together with communications technology has enabled authors to create digital libraries and hypertext publishing systems. ${ }^{1}$ Active development of such systems is now underway. ${ }^{2}$ While some difficult technical problems must be solved to build these systems, technical obstacles are thought to be surmountable. Less clear, however, is what kind of intellectual property scheme can be used to make digital library or hypertext publishing systems commercially viable.

An intellectual property system works well when it embodies a reasonably accurate model of how people are likely to behave. Copyright law is based on a relatively simple and straightforward model of author and reader behavior. ${ }^{3}$ Authors are motivated to produce interesting and

* An earlier version of this article was published in the 1991 PROC. OF THE ACM CONF. ON HYPERTEXT. Use of material from the earlier version is by the permission of the Association for Computing Machinery. The authors thank Mark Bernstein, Joe Farrell, Anna Belle Lieserson, Peter Martin, James Moore, and several anonymous reviewers for their helpful criticism.

** Professor of Law, University of Pittsburgh School of Law.

*** Chief Scientist, Passage Systems, Mountain View, Cal.

1. See, e.g., Pamela Samuelson, Some New Kinds of Authorship Made Possible by Computers and Some Intellectual Property Questions They Raise, 53 U. PITT. L. REV. 685 (1992).

2. See CAROLIne ARMS, CAMPuS STRATEgies for LIBRARIES AND Electronic INFORMATION (1990); Douglas C. Engelbart, Knowledge-Domain Interoperability and an Open Hyperdocument System, 1990 PROC. OF THE CONF. ON COMPUTER-SUPPORTED COOPERATIVE WORK 143; ROBERT E. KAHN \& VINTON G. CERF, THE DIGITAL LIBRARY PROJECT (1988); Christine M. Neuwirth et al., Issues in the Design of Computer Support for Co-authoring and Commenting, 1990 PROC. OF THE CONF. ON COMPUTER-SUPPORTED COOPERATIVE WORK 183.

3. We concentrate here on incentive structures for authors and readers rather than on those for publishers and other institutions involved in the creation or distribution of copyrighted works. The incentives for these other actors derive, in our view, from the incentives aimed at authors and readers. Publishers, for example, are protected by the 
valuable texts and to make these works available to others by copyright's reassurance that authors can control the sale of copies of their works. Readers are motivated to purchase the texts, or to urge institutions such as libraries to purchase the texts, so that they can have access to the work. Authors have generally had little control over what uses readers make of the copies after the first sale of the work to the public. ${ }^{4}$ Commentators on U.S. copyright law have sometimes regarded this lack of control over uses as a virtue..$^{5}$ But while it can be said that the absence of copyright control over uses has promoted the dissemination of knowledge, ${ }^{6}$ the truth is that in the print world it is infeasible to maintain meaningful control over uses anyway.

Copyright should be accounted a great success at modeling author and reader behavior, for the basic framework of this law has lasted nearly three hundred years. During this period, copyright industries have flourished and copyright law has broadened to include a wide variety of intellectual products besides those manufactured by printing presses. ${ }^{7}$

While the copyright model is being utilized for all manner of texts in digital form, the behavior of authors and readers is being changed by the new digital technologies. It is becoming increasingly likely that some adjustments will have to be made in the copyright model to make digital libraries and hypertext publishing environments as commercially viable as the print industries have been. But few new models have yet been constructed, and work in this direction has only just begun. ${ }^{8}$

rights authors get from copyright law that authors typically assign or license to them. Professor Henry Perritt has identified ten value-added functions in the publication process, whether in print or electronic form, asserting that incentives are important for all of these functions. See Henry H. Perritt, Jr., Tort Liability, the First Amendment, and Equal Access to Electronic Networks, HARV. J.L. \& TECH., Spring 1992, at 65, 68-69.

4. Although copyright owners have an exclusive right to control the distribution of copies of their works, Copyright Act of 1976, 17 U.S.C. $\S 106(3)$ (1988), this right of control is generally "exhausted" after the owner's first sale of the work to the public. 17 U.S.C. $\S$ 109.

5. See, e.g., Ralph S. Brown, Eligibility for Copyright Protection: A Search for Principled Standards, 70 MINN. L. REV. 579, 588-89 (1985).

6. Dissemination of information is an important goal of the copyright system, See, e.g., OFFICE OF TECHNOLOGY ASSESSMENT, INTELLECTUAL PROPERTY RIGHTS IN AN AGE OF ELECTRONICS AND INFORMATION (1986) [hereinafter OTA REPORT].

7. Until 1976, the U.S. copyright statutes named specific categories of works for which copyright protection was available. Each time a new medium for expression (such as photography or motion pictures) was invented, the copyright statute had to be amended. The current copyright statute protects all original works of authorship from the moment of their first fixation in a tangible medium. 17 U.S.C. $\$ 102(a)$.

8. See InFormation NeTWORKING INSTITUTE, CARNEGIE MELlON UNIVERSITY, DEVELOPMENT PLAN FOR AN ELECTRONIC LIBRARY SYSTEM (1991) [hereinafter INI 
After a brief discussion of some characteristics of informational works in digital form that challenge existing intellectual property systems, this Article will discuss how some emerging electronic information services are presently regulating intellectual property rights. It will then try to foresee how such rights might be handled if digital libraries become, as some in the technical community foresee they will, hypertext publishing systems (that is, systems in which users can become authors by linking portions of the digital library's contents-with or without any additional content contributed by them-whose link-based work can be published within the digital library).

The most innovative and well-developed model for how intellectual property rights might be dealt with in a hypertext publishing system is that proposed by Ted Nelson (a hypertext developer and visionary-indeed the person who coined the term hypertext for which a whole field of endeavor is now known) in his book Literary Machines. ${ }^{9}$ This book describes the Xanadu hypertext publishing system designed by Nelson, which was to have been commercialized by Autodesk, a software publishing firm. ${ }^{10}$ Although the Article ultimately concludes that the Xanadu intellectual property rights model is flawed because it does not accurately reflect how authors and users would likely behave, it praises a number of aspects of Nelson's model and the innovative concepts it embodies. The authors hope this critique of the Nelson model will aid in the formulation of a new conception about how intellectual property rights can be dealt with so that digital libraries and hypertext publishing systems can become commercially viable.

\section{DIGITAL MEDIA AND INTELLECTUAL PROPERTY LAW}

Six characteristics of works in digital form seem likely to change

REPORT]; CORPORATION FOR NATIONAL RESEARCH INITIATIVES, KNOWBOTS IN THE REAL WORLD: WORKSHOP ON THE PROTECTION OF INTELLECTUAL PROPERTY RIGHTS IN A DIGTTAL LIBRARY SYSTEM (1989); PAUl ZAHRY \& MARVIN SIRBU, THE PROVISIONS OF SCHOLARLY JOURNALS BY LIBRARIES VIA ELECTRONIC TECHNOLOGIES (1989).

9. THEODOR H. NELSON, LITERARY MACHINES (87.1 ed. 1987).

10. Autodesk has recently decided to divest itself of its subsidiary, which was developing Xanadu, in order to concentrate on its core business. See Earnings Decline Prompts Autodesk Spinoffs, PC WK., Aug. 24, 1992, at 134. Nelson still intends to commercialize a version of Xanadu in the near future. See THEODOR H. NELSON, LITERARY MACHINES (93.1 ed. 1993) (preface). 
significantly the contours of intellectual property law, especially copyright. ${ }^{11}$ The ease with which such works can be replicated and the ease with which they can be transmitted and accessed by multiple users are the first and second of these characteristics. These characteristics would seem to create strong incentives for copyright industries to move away from their traditional focus on the sale of copies, and toward greater control over uses of protected works. That it is now feasible to control uses through controlling access to computer systems containing works in digital form will also affect this trend.

A third characteristic of digital works is the ease with which they can be manipulated and modified. While this plasticity offers users some important advantages over the print medium (printed works are sometimes too fixed to be maximally usable), copyright law is more geared toward dealing with works that are permanently fixed. The law may need to be adjusted to cope with the new benefits and new problems that this plasticity will entail, such as providing guidelines for circumstances in which plastic uses of digital information are permissible. ${ }^{12}$

A fourth characteristic is the breakdown of copyright distinctions among different kinds of works when they are in digital form. The copyright statute identifies seven categories of protected works, each of which has somewhat varying degrees of protection. ${ }^{13}$ Is a hypertext version of Mozart's Magic Flute that contains the music, the libretto, textual commentary, pictures of Mozart, and other media a "literary work," a "musical work," a "sound recording," a "pictorial work," or an "audiovisual work" ?" The answer to this question under copyright law cannot be all of the above-even if it really is. Copyright's classification scheme, oriented as it is toward the appearance of works and the medium in which they are embodied, seems in need of adjustment if the statutory differences are absent from the digital representation.

11. Pamela Samuelson, Digital Media and the Changing Face of Intellectual Property Law, 16 RUTGERS COMPUTER \& TECH. L.J. 323 (1990).

12. A friend developed a device that converts signals produced when sound recordings are played into patterns of light generated by laser in accompaniment to the music. Are these light patterns copies or derivative works of the sound recording? Is it fair use to generate them? If he commercialized this device, would he be liable for contributory infringement? For other digital transformation examples, see Pamela Samuelson, Some Challenges New Information Technologies Pose for Existing Intellectual Property Systems, 1991 PROC. OF THE THIRD INT'L SYMP. ON LEGAL PROTECTION OF COMPUTER SOFTWARE 453.

13. 17 U.S.C. $\$ \S 102(a), 106-120$.

14. Warner New Media has such a product. See Ronald Rosenberg, The MacWorld Galaxy, BOSTON GLOBE, Aug. 5, 1992, at 65. 
Because so many of the exclusive rights and special privilege provisions in the copyright statute depend on the category of the work, they will need some refinement to deal with digital multimedia works. ${ }^{15}$

A fifth characteristic is that digital works are virtually invisible to users/readers. Works in digital form are stored as a sequence of high and low voltage signals in computer memory. They cannot be perceived or read by humans except with the aid of a user interface. One cannot tell from viewing one portion of such a work on a computer screen how large the work is, nor can one navigate through the text unless navigation aids have been specially constructed in software to permit this. Fortunately, the sixth and final characteristic of digital media is that they allow new kinds of search and linking activities to be achieved. This characteristic has given rise to new classes of protected intellectual property products, including hypertexts.

Intellectual property protection for innovative aspects of new kinds of digital works, such as software user interfaces and hypertext navigation aids, has been a subject of significant controversy, both on copyright and patent fronts, and seems likely to remain so for the foreseeable future. ${ }^{16}$ Despite repeated Supreme Court rulings that algorithms are unpatentable ${ }^{17}$ and evidence that practitioners believe strong protection by copyright and patent will have a negative effect on the software industry, ${ }^{18}$ the U.S. Patent Office has been issuing many software patents in recent years, some of which are for functions and user interface features for hypertext systems. ${ }^{19}$ Some court decisions have taken such an expansive view of the scope of copyright protection that reuse of almost anything but very high level abstractions in software would seem dangerous, ${ }^{20}$ although other decisions have taken a far narrower view, seeming to confine

15. See 17 U.S.C. $\S \S 106-120$.

16. The authors have elsewhere reported the results of surveys on intellectual property rights issues-one of the members of the user interface design community, and one of the computer graphics community. See Pamela Samuelson \& Robert J. Glushko, Comparing the Views of Lawyers and User Interface Designers on the Software Copyright "Look and Feel" Lawsuits, 30 JURIMETRICs. J. 121 (1989); Pamela Samuelson et al., Developments on the Intellectual Property Front, 35 CoMM. ACM 33, 34-37 (June 1992).

17. See Pamela Samuelson, Benson Revisited: The Case Against Patent Protection for Algorithms and Other Computer Program-Related Inventions, 39 EMORY L.J. 1025 (1990). 34.

18. See Samuelson, Developments on the Intellectual Property Front, supra note 16, at

19. See, e.g., Sharon R. Garber et al., Intelligent Optical Navigator Dynamic Information Presentation and Navigation System, U.S. PAT. No. 4,905,163, issued Feb. 27, 1990.

20. See, e.g., Whelan Assoc., Inc. v. Jaslow Dental Lab., Inc., 797 F.2d 1222 (3d Cir. 1986). 
"expression" to that which would readily be viewed as expressive in traditional categories of works. ${ }^{21}$ Some decisions have recognized that computer software is difficult to fit in the traditional copyright mold. ${ }^{2}$

\section{MODELS OF AUTHOR AND READER BEHAVIOR IN RECENT ELECTRONIC INFORMATION SYSTEMS}

Some clues about how authors and readers might behave in digital libraries and hypertext publishing systems can be perceived by looking at how people currently use computer bulletin boards, computer data bases, and other information services and electronic mail systems. Instead of viewing these systems as technical precedents, it is instructive to consider them as experiments in developing appropriate models for intellectual property and reader/user/author behavior that might be adapted for more ambitious applications such as Xanadu.

\section{A. Prodigy and CompuServe}

Prodigy and CompuServe are commercial services that provide a variety of bulletin boards, electronic mail, information services, and entertainment. $^{23}$ They embody significantly different models of user behavior, and their pricing strategies are markedly different. Prodigy targets the consumer and home markets, and treats its users as relatively passive information consumers who do not interact much with each other. Prodigy offers users access to many different kinds of information, as well as bulletin boards, electronic mail, and some entertainment. Its services are made available for a fixed monthly fee. Usage-insensitive pricing is made possible by the paid advertising that Prodigy presents along with nearly every screen of information displayed to users. When Prodigy imposed a usage-pricing scheme for sending electronic mail, many users felt that their contract with Prodigy, as well as their "free

21. See, e.g., Computer Assoc. Int'l v. Altai, Inc., 23 U.S.P.Q.2d (BNA) 1241, 982 F.2d 693 (2d Cir. 1992).

22. Id.

23. See, e.g., Jeff Ubois, On-Line News Services Give Users Information on Demand, MACWEEK, Nov. 16, 1992, at 91 (discussing different classes of services available from online information systems and their pricing structures). 
speech rights," had been violated..$^{24}$

In contrast, CompuServe has been oriented toward business and professional users and always had usage-based pricing based on connect time. CompuServe information services are specifically focused, organized into a complex hierarchy of bulletin boards and data bases, many of which are moderated by an expert, who in some circumstances is compensated by CompuServe. This finer-grained categorization enables CompuServe to impose surcharges for supposedly more timely or valuable information, but its user population is presumably used to paying for information according to its value. Users engage in heated electronic dialogues with one another on bulletin boards, commenting on and criticizing one another's postings.

Both Prodigy and CompuServe place some limits on user downloading. Some materials, such as shareware or public domain software from both sources, can be downloaded without restriction, but other materials are restricted. The two systems differ, however, in the locus of restrictions. Prodigy is a centralized service which means it sets and enforces the downloading policy. CompuServe, by contrast, has a more decentralized policy because it is essentially an umbrella organization for a number of information services, and these services often have their own downloading policies. Quite recently, however, both Prodigy and CompuServe have expanded user opportunities to download materials, although this adds to the cost of the service. ${ }^{25}$

\section{B. The Internet}

The Internet is a vast network of networks that interconnect thousands of computing sites in government, industry, and academia. The Internet has evolved from primarily providing electronic mail services to become the infrastructure for significantly broader services of information

24. When Prodigy users began using electronic mail messaging and bulletin boards to organize a protest of pricing policy changes, Prodigy cut off service to the protestors which caused users to charge that the firm was interfering with free speech interests. More recently, Prodigy came under fire from subscribers for closing down a bulletin board called "Frank Discussions." See Sex Talk Prompts Prodigy to Shutter Bulletin Board, CHICAGo TRIB., Feb. 1, 1993, at B2. A lawyer would feel compelled to point out that Prodigy, as a private firm, is not circumscribed by the First Amendment, but within the technical community, feelings ran high that speech interests were implicated.

25. See Ziffnet Provides Link to Prodigy, Offers Access to Support Databases, PC WK., Nov. 30, 1992, at 83. 
exchange and collaborative work. ${ }^{26}$ Like CompuServe, the heart of the Internet is a vast collection of newsgroups in which participants from around the world post and comment on messages. Some people take on the role of newsgroup moderators, but the overwhelming majority of newsgroups are unmoderated.

Author and reader behavior on the Internet are largely governed by norms or "netiquette" that have evolved over time and that are enforced both by system administrators and by the informal but effective sanctions of "flames" (critical messages) directed at violators. Included in these norms are rules about selecting newsgroups in which to post messages, sensitivity to authors of posted messages when citing or responding to them, and other matters that affect both authors and readers. ${ }^{27}$

Users of the Internet vary greatly in their perception of intellectual property laws as they apply to this new kind of publishing system. Some users, especially new users who are college students, act as if the Internet services and the information that can be had by exploring the Internet are completely free. ${ }^{28}$ In fact, each host machine that serves as an Internet site has to pay a fee for the privilege. Institutions recoup these fees as well as other costs associated with use of host machines by passing them on, even if the costs are not immediately evident because they may be borne by a particular unit of the institution, rather than directly by those who use the machine for Internet services.

Those who post information not authored by them on Internet bulletin boards or in electronic newsletters delivered by Internet sometimes do so with a conspicuous notice that it is being posted without copyright permission, thereby asserting the poster's view of an appropriate scope of fair use. But some who post materials on the Internet explicitly assert copyrights on the messages that they post. And it has become increasingly common for electronic journals distributed on the Internet to contain a notice that those who contribute items to the journals are responsible for obtaining whatever copyright permissions might be needed. Although "net" users generally regard it as fair to download items from the bulletin board for one's personal use, and even to send a copy to a friend who might otherwise not see the item, it is considered bad manners (or worse) to redistribute more widely someone else's posting without its author's

26. See BUILDING INFORMATION INFRASTRUCTURE (Brian Kahin ed., 1992).

27. See ED KROL, THE WHOLE INTERNET: USER's GUIDE \& CATALOG 31-38 (1992).

28. These same college students would likely be more sensitive to issues of plagiarism and infringement applicable to printed works when they write term papers. 
permission. Still, it is worth noting that because "the net" is so vast and the number of its users so large, it can be extremely difficult to police it for copyright purposes.

Authors who distribute works on the Internet are generally not paid to publish, and receive no royalties. ${ }^{29}$ Nor do readers generally have to pay to read items on the Internet. But it is fair to state that many Internet activities are being paid for (or at least subsidized) by Internet participants' employers. Hence, it can be argued that anything posted on the Internet that is work-related is the intellectual property of the employer who provides access to the Internet by paying for the computers and telecommunications infrastructure. ${ }^{30}$ Employers may feel that the value of the information their employees glean from the Internet outweighs the costs of the time to obtain it, but it is unlikely that many employers explicitly make this analysis. ${ }^{31}$

In addition to electronic mail and newsgroups, the Internet now supports several innovative services that enable it to function as a distributed digital library with vast holdings. ${ }^{32}$ If an Internet site chooses to make some of its information publicly available, a user on another site can use the anonymous FTP (file transfer protocol) mechanism to retrieve it. ${ }^{33}$ Other experimental services, some with fanciful names like Archie, Gopher, and World Wide Web, build upon FTP to provide users with a worldwide index so that they can find sites that offer the information they seek. ${ }^{34}$ The WWW service allows users to retrieve what they want even if they cannot directly connect to the site that stores it. These new services are being enthusiastically embraced in the academic and research communities of the Internet, but they pose even more problems for intellectual property rights because they erode the boundaries between

29. This seems likely to change now that the Internet is opening up to commercial services. Work is underway to develop models for Internet billing servers. See Information Networking Institute, Camegie Mellon University, Internet Billing Service Design and Portotype Implementation, 1992 PROC. OF THE WORKSHOP ON TECH. STRATEGIES FOR PROTECTING INTELL. PROP. IN THE NETWORKED MULTIMEDIA ENV'T 1.

30. Copyright's "work made for hire" provisions treat employers as authors of employees’ work. See 17 U.S.C. §§ 101, 201.

31. The authors have heard reports that when Xerox tried to crack down on the use of the net for personal communications at its Palo Alto Research Center, protests from researchers were so strong that the firm rescinded its initial directive.

32. See generally BRENDAN P. KEHOE, ZEN AND THE ART OF THE INTERNET: A BEGINNER'S GUIDE (2d ed. 1993); John S. Quarterman, In Depth: The Internet, COMPUTERWORLD, Feb. 22, 1993, at 81, 81-83.

33. See KROL, supra note 27 , at $59-90$.

34. Id. at 155-68, 189-242. 
public and commercial information sources.

\section{Lexis and Westlaw}

Lawyers have had access to digital libraries of legal materials for well over a decade, thanks initially to the farsightedness of a paper manufacturer, which perceived a market opportunity for providing electronic access to judicial opinions, statutes, regulations, and other legal materials. This manufacturer formed Mead Data Central, whose Lexis data base lawyers use regularly. Like so many other print publishers, the major legal print publisher, West Publishing, did not see the market opportunity for electronic information services until after Lexis had become a major success. Although a late entrant to the business, West has succeeded in designing a digital library of legal materials that offers some services, particularly the key numbering system that West had long used in print, that give it some competitive advantage. ${ }^{35}$

The initial pricing scheme employed by Lexis and by West was similar to that used by CompuServe: usage-based pricing based on connect-time. This pricing strategy worked particularly well because lawyers could typically pass these charges on to clients. Over time, both services developed pricing strategies for institutions, such as law schools, where connect-time charges could not be passed on. Both services also now permit downloading of electronic versions of legal materials as well as printouts of selected materials. No special charges seem to be levied for these services, although usage-based charging would absorb the costs through connect-time, and institutional subscription pricing would be based on a predicted quantum of such uses.

There is no technical reason why these two digital libraries could not become hypertext publishing systems. Their considerable financial success might suggest that this extension would be a natural one, and indeed, at least one author has tried to make them become so. Professor

35. The most well-known intellectual property issue associated with these two data bases is undoubtedly the litigation between them over Mead's efforts to insert references to the West books' pagination in Mead's electronic versions of the cases. West claimed that the pagination was an "expression" of its arrangement of the cases, the copying of which was copyright infringement. The case settled after an appellate court upheld a ruling in West's favor. See West Pub. Co. v. Mead Data Cent., Inc., 799 F.2d 1219 (8th Cir. 1986). The ruling has been strongly criticized by commentators. See L. Ray Patterson \& Craig Joyce, Monopolizing the Law: The Scope of Copyright Protection for Law Reports and Statutory Compilations, 36 UCLA L. REv. 719 (1989). It does not seem consistent with the Supreme Court's ruling in Feist Publications, Inc. v. Rural Tel. Serv., Inc., 111 S.Ct. 1282 (1991). 
Peter Martin of the Cornell Law School sought to bring about this kind of expansion of legal data base functions by creating a hypertext treatise on Social Security Law on the Lexis system. ${ }^{36}$ Because Lexis had no particular incentive to promote its use, Martin eventually negotiated an arrangement by which he could "port" the treatise to a CD-ROM so it could be commercialized. Professor Henry Perritt of Villanova Law School has also proposed hypertext publishing systems built on top of digital libraries of legal materials as a way to produce electronic casebooks. ${ }^{37}$ But except for the work of a few pioneers, such as Professors William Andersen of the University of Washington Law School, William Boyd of the University of Arizona Law School, and Ronald Staudt of the Chicago-Kent Law School, hypertext has yet to come to the field of law. The richly intertextual nature of law makes it a natural field for hypertext applications, and perhaps ways can be found to create them on top of a digital library of legal materials such as Lexis or Westlaw, and make them commercially viable..$^{38}$

\section{THE INTELLECTUAL PROPERTY SYSTEM IN XANADU}

The most complete proposal for making digital library or hypertext publishing systems commercially viable has come from Ted Nelson. For over two decades, Nelson has been writing and talking about a proposed system called Xanadu, which he envisioned as a vast digital library containing all of the world's literature. ${ }^{39}$ Because Xanadu would allow

36. Martin's treatise was published on Lexis on June 1, 1991. Martin has prepared a guide to instruct on the use of executable references on Lexis.

37. Henry Perritt spoke about his "mother of all casebooks" concept at the January 1992 AALS Annual Meeting's session on electronic publishing that was co-sponsored by the Sections on Computers and the Law and on Intellectual Property Law. Perritt envisioned electronic case compilations as the "mother" component and professor-created links from case to case built on top of the "mother" component as a way of creating customized casebooks.

38. It is worth noting here that Columbia Law School has just announced plans to develop a digital law library, much of the contents of which would be derived from scanning in deteriorating printed works and other public-domain materials. This material will be stored on a supercomputer manufactured by Thinking Machines Corp. and will be accessible to members of the law school community with computers and access to a library password. This system will have a more refined search engine than is available from Lexis or Westlaw. See William M. Bulkeley, Libraries Shift from Books to Computers, WaLl ST. J., Feb. 8, 1993, at B6. Chicago-Kent Law School has also significantly computerized its law-library operations. Id.

39. Nelson has described Xanadu in numerous publications, presentations, and interviews. 
users to create new and derivative documents via links, Xanadu is also a hypertext publishing system. Xanadu can usefully be understood as an attempt to create an institution that will be writing environment, publishing environment, library, and bookstore in one.

Despite his visionary reputation, Nelson is practical enough to realize that the commercial success of the Xanadu proposal critically depends on the way it deals with intellectual property issues. The intellectual property system in Xanadu has sometimes been summarized in writings about the Xanadu system in popular magazines, ${ }^{40}$ but has been subject to little serious analysis.

After a brief description of how Xanadu would deal with intellectual property rights issues, this Part will discuss some respects in which the Xanadu proposal differs from that which is reflected in the existing copyright system. Xanadu contains some interesting ideas about how to solve certain problems with digital library and hypertext publishing systems, but some aspects of the Xanadu model of author and user behavior may be unworkable. Nevertheless, Nelson's analysis suggests some respects in which intellectual property systems might have to adapt to make digital libraries and hypertext publishing systems commercially viable.

\section{A. Xanadu's Revenue Sources and Mechanisms}

Nelson envisions revenues being generated in Xanadu from two sources: first, from authors who would pay fees for renting space for their documents in the Xanadu system, and second, from users who would pay fees based on their usage of the system. Nelson expects that authors will want to put their documents into the Xanadu system because once the documents are in the system, authors will be able to earn royalties whenever users make use of their documents. Between ten and twenty percent of usage fees would go to authors whose documents are accessed by users; the rest would go to the system to recoup costs and

Many of the publications have appeared in multiple editions, so it is hard to identify any one work as the definitive specification for Xanadu. We derive our view of his model from the 87.1 edition of LITERARY MACHINES. NELSON, supra note 9. A commercial version of Xanadu might well differ from Nelson's vision, but it is instructive to consider Nelson's proposal in its "pure" form to understand some of the changes and compromises that the firm that commercializes this system will likely have to make.

40. Xanadu, RELEASE 1.0, July 13,1989, at 3. 
make profits. ${ }^{41}$ Nelson intends for usage fees, and consequently the royalties as well, to be set on a per byte delivery basis for administrative convenience. ${ }^{42}$ Nelson expects that people will pay to use the Xanadu system, because not only will it contain as much of the world's literature as Nelson can get into it, but there will also be legion opportunities in the Xanadu system for users/browsers/readers to make money by adding value to the system through their creative uses of the system.

There are two main means by which Nelson intends to let users make money in the Xanadu system. One is by making derivative works of documents already in the system. This would include creating new versions of other authors' documents, creating compound documents consisting of portions of a number of different documents, or creating commentaries on other documents in the system. By creating derivative documents, users would become system authors themselves, and thereby become able to earn royalties when other users access their derivative documents. No special permission would be needed to make derivative documents from other authors' documents, for Nelson will make it a condition of storing documents in Xanadu that authors agree to allow others to make whatever derivative uses they want of published documents in the system. ${ }^{43}$

Nelson relies on two factors to motivate authors to agree to allowing derivatives to be made of their documents. One is that they will then be able to do to others' documents what others can do to theirs. But more importantly, when a third party accesses the derivative document on Xanadu, the author of the underlying document, as well as the author of the derivative document, will earn a royalty, because the derivative document will be connected to the original document; bytes from both will be called up when third parties access the derivative document. Hence, both authors will receive royalties.

A second way for users to generate revenues when using the Xanadu system will be by creating links between or among documents in the system. Nelson expects some links to be very elaborate, such as a specialized index to certain classes of documents in the system. Other

41. If public-domain documents, such as Shakespeare's plays, are accessed, the author portion of the fee will go into an "author's fund" for scholarships or the like. NELSON, supra note 9 , at $5 / 13$.

42. "From an administrative and programming point of view, it is cleaner and more verifiable for royalties to be fixed per byte shipped." Id. at $4 / 5$.

43. Id. at $2 / 42$. 
links may be modest, such as a connector between two documents. User links between documents, in effect, become new documents in the system. Each time other users traverse a set of links, the link author will receive a royalty, as will the authors of the documents on either end of the link. Although Vannevar Bush was the first to perceive that information trailblazers would be needed for computerized information systems, ${ }^{44}$ Nelson deserves credit for recognizing the need to give incentives to information pioneers to cut paths through the invisible contents of a digital library.

Nelson's scheme would also provide authors with the opportunity to store private as well as published documents in the Xanadu system. Authors would be able to decide who could have access to private documents and under what conditions. But Nelson envisions that authors of private documents would generally make them available for linking. Private documents could be withdrawn without difficulty from Xanadu by their authors. The same will not be true for published documents because of the effect withdrawal would have on the interests of authors who have linked to or otherwise built upon the foundation of the published document. $^{45}$

Nelson attempts to create a strong incentive for authors to publish their documents in the Xanadu system by making system royalties unavailable to authors for private documents, even those with unrestricted distribution (i.e., from which derivatives can be made, and to which links can be constructed). Because publication imposes obligations on the Xanadu operator and the author, publication of a document in the Xanadu system is a formal event, requiring a signature of the author on a form affirming the intent to publish the work. ${ }^{46}$

\section{B. Comparing Xanadu and the Copyright System}

Nelson refers to copyright in a positive way in a number of passages in his book, and takes care to establish a plausible case that nothing in Xanadu violates existing copyright law. Xanadu gives authors new ways to generate revenues from their works-even some that copyright might not provide-and so aims to create incentives to authorship, revealing a

44. Vannevar Bush, As We May Think, ATLANTIC MONTHLY, July 1945, at 105.

45. NELSON, supra note 9 , at $2 / 43$.

46. Id. 
predisposition in keeping with traditional copyright incentives. But the Xanadu system is more different from copyright than might be apparent from a cursory examination.

\section{Compensation Based on Uses, Rather than Distribution of Copies}

One difference between the Xanadu intellectual property system and traditional copyright is that Xanadu aims to derive revenues for authors by charging for each and every use of their documents, rather than, as has traditionally been done in copyright industries, on the sale or other commercial distribution of copies of copyrighted works. Many commercial computer data bases do much the same thing. Such arrangements seem likely to become increasingly common for works in digital form.

\section{Blurring the "Idea" and "Expression" Distinction and Eliminating "Fair Use"}

A more novel set of differences from copyright flow from Xanadu's treatment of links. Fundamental to the copyright regime is a distinction between "ideas" (which are unprotected by copyright law) and "expression" (which copyright protects). Under the copyright regime, authors generally do not expect remuneration whenever other authors comment on, quote from, use ideas from, or make reference to their work. The statutory fair use provision has been interpreted as allowing even literal copying of copyrighted text if the amount taken is relatively small, especially if the taking is for research, educational, or critical purposes. ${ }^{47}$ Only if other authors take a fairly hefty chunk of "expression" from the protected work do copyright holders expect compensation. ${ }^{48}$

In Xanadu, information can be included in a document by linking. Because of this, Xanadu draws a different line than the print world would about what information to count as a single work. Even if Xanadu had a fair use provision, the lack of separateness among documents would complicate the determination of what constitutes fair use. But Xanadu allows no fair use copying. Authors in the Xanadu system will get

47. 17 U.S.C. $\$ 107(3)$; See Wright v. Warner Books, 748 F. Supp. 105 (S.D.N.Y. 1990), aff'd, 953 F.2d 731 (2d Cir. 1991).

48. Even for printed works, however, there is no exact boundary between "small" and "hefty" copying under fair use provisions, and some authors and publishers avoid the issue by obtaining rights to use even a small quantity of words. 
royalties based on how many bytes were linked to-merely for being linked to. This aspect of Xanadu prefigures an intellectual property system that compensates authors without regard to whether chunks of expression have been appropriated. In time, this would seem likely to undermine the "idea/expression" distinction that has been a staple part of the copyright system.

\section{Treating Linking as Authorship}

Nelson's decision to treat linking as a kind of authorship-that is, as an intellectual activity that should not only be encouraged, but should serve as the basis for earning royalties when users traverse the links-also seems to diverge somewhat from the traditional copyright model. While an extensive set of links, such as an index, might readily be protectable by traditional copyright law as a compilation, many of the kinds of links that Nelson would treat as works of authorship might be unprotectable under traditional copyright law. A link between a passage in document $A$ and a passage in document $B$ might, for example, be considered a "discovery" that the statute says copyright cannot protect. ${ }^{49}$ Traditional copyright law would also not regard it as a compensable use of a copyrighted work for readers to traverse the links among documents referred to in a printed article. ${ }^{50}$ Yet link authors in Nelson's scheme would be compensated for others' traversal of their links.

\section{Use Rights vs. Rights To Exclude}

Nelson, like many others who are not lawyers, finds it natural to think of intellectual property rights in terms of what uses of works should give rise to author compensation. This intuitive "rights to do" framework is used by Xanadu. The law tends to define intellectual property rights in a somewhat different way. The law focuses on what rights owners have to exclude other people from doing certain kinds of things with the protected work.

Copyright law defines the ownership rights of authors by saying what kinds of activities they can stop unauthorized people from doing. Chief

49. 17 U.S.C. \& 102(b); see Feist Publications, Inc. v. Rural Tel. Serv., Inc., 111 S. Ct. 1282 (1991) (Facts are excluded from copyright protection as "discoveries.").

50. Samuelson, supra note 11, at 339. 
among copyright's exclusive rights are these: controlling the making of copies and derivative works of the protected work and distributing copies or derivative works. ${ }^{51}$ The only exclusive right Xanadu seems to contemplate is whether or not to put a document into the Xanadu system in the first place. Xanadu is more like a compulsory-license system than an exclusive-rights system. While U.S. copyright law does contain some compulsory-license provisions, ${ }^{52}$ compulsory licenses are generally an anathema to owners of intellectual property rights because the license fee generally bears little or no relation to the price obtainable if the issue were left to the market.

\section{Unlimited Duration}

The Xanadu system seems to contemplate no end to the duration of author rights. As long as authors (or their heirs) continue to pay for storage on this system, Xanadu will continue to pay royalties for uses of the documents. Under the U.S. Constitution, copyright can only be granted to authors for limited times. ${ }^{53}$ Upon expiration of the copyright, the work is in the public domain. While Nelson may not have consciously rejected this aspect of copyright in the Xanadu system, his description of the system reveals that he does not intend to reduce usage fees for accessing public domain materials. Royalties from them go into the "author's fund" over which he undoubtedly will exercise some control. ${ }^{54}$

\section{Making Publication an Important Formal Event (Again)}

Publication is an important formal event in the Xanadu system. Under previous U.S. copyright laws, authors generally only "copyrighted" their works when the work was published..$^{55}$ A formal copyright notice had to appear prominently in all publicly distributed copies of the work, or the claim of copyright would be forfeited. ${ }^{56}$ The Copyright Act of 1976

51. 17 U.S.C. § 106.

52. See, e.g., 17 U.S.C. $\S \S 115-116$.

53. U.S. CONST. art. I., \& 8, cl. 8.

54. See NELSON, supra note 9 , at $2 / 46$.

55. Prior to 1976 , unpublished works were principally protected from unauthorized distribution by state "common law copyright" protection. See Ralph S. Brown, Unification: A Cheerful Requiem for Common-Law Copyright, 24 UCLA L. REv. 1070 (1977).

56. See generally RALPH S. BROWN \& ROBERT C. DENICOLA, CASES ON COPYRIGHT 2448 (5th ed. 1990) (concerning the historical importance of publication and copyright notice in U.S. copyright law). 
permitted inadvertent omissions of copyright on a small number of copies of the work to be remedied, but extended protection to all original works of authorship from the moment of their first fixation in a tangible medium..$^{57}$ In 1989 , in order to bring U.S. copyright law into compliance with requirements of the Berne Convention, the notice requirement as a precondition to protection of published works was dropped. ${ }^{58}$ Copyright notices are now important only for incidental purposes, such as foreclosure of a defense of innocent infringement. ${ }^{59}$ Publication used to be a very important event in U.S. copyright law, but more recently, this law has made publication into a virtual nonevent. ${ }^{\infty}$ By making publication into a significant event, Nelson's scheme resembles "old" copyright more than "new" copyright.

Nelson's decision to make publication a formal event in Xanadu is necessary because publication in Xanadu would create a contract between the Xanadu system and the author to guarantee the existence of the published document for a period of time. ${ }^{61}$ This provides an integrity to links and citations generally absent in the print world, where only law reviews, with their armies of student citation-checkers, assure the reader that the cited document exists and supports the proposition for which it was cited.

\section{Contracting To Permit Derivative Works}

Yet another respect in which the Xanadu system diverges from the standard copyright model is in proposing to contract with all authors whose works would be stored in the Xanadu system so that users could make derivative documents from documents in the system. ${ }^{62}$ Varying the "default setting" of copyright by contract is not, in itself, a novel thing. The motion picture industry is an example of a copyright industry that has

57. 17 U.S.C. $\S \S 302(a), 405$.

58. See BROWN \& DENICOLA, supra note 56 , at 36 (regarding changes to the notice requirement to implement responsibilities under the Berne Convention).

59. See 17 U.S.C. $\S 401$ (d).

60. The date of first publication still affects the copyright duration for some works and other fine details. See BROWN \& DENICOLA, supra note 56, at 29. Publication may come to have new importance in copyright law as a way to determine whether trade secret rights can be claimed in copyrighted works. This is of special concern to software developers who claim both copyright and trade secret rights in mass-marketed object code.

61. For a discussion of the process Xanadu would require in order for an author to withdraw a document from publication, see NELSON, supra note 9, at 2/43.

62. Id. at $2 / 42$. 
historically depended for commercial success on contract-based distributions of copies, rather than on the outright sale of copies that has typified most copyright industries. ${ }^{63}$

Nelson's scheme is novel in proposing to use a contract-based scheme for commercial distribution of written texts, the prototypical subject matter of copyright, and in seeking to permit the widest derivative uses of documents in the system. Copyright, by contrast, has become rather stingy about derivative uses of anything but abstract ideas from protected works. ${ }^{64}$

\section{Conclusion}

In short, the Xanadu intellectual property system is more different from copyright than one might think from reading Nelson's books. Nelson has a number of important insights about linking. There probably is a need to create incentives for users of digital library systems to engage in linking activities. Linking should probably be treated as a form of authorship in digital libraries and hypertext publishing systems. And the traversing of links by other users probably should serve as a basis for compensation to link authors. Nelson is probably also right in thinking that authors should not be able to forbid users of published documents from linking to their documents. These are his most important and original contributions to current thought about how intellectual property issues should be handled for digital library and hypertext publishing systems. But some aspects of the Xanadu intellectual property system depend on assumptions about how authors and readers will behave that may be incorrect.

63. Only recently has the motion picture industry become more like traditional copyright industries in its sales of videocassettes.

64. At one time, copyright law did not forbid translation of a work from one language to another or preparing a dramatic play from a copyrighted novel. See OTA REPORT, supra note 6, at 190-91. Over time, these acts were made unlawful unless the author had consented. Id. Nowadays, one is only likely to be found a noninfringer if a subsequent work is based on the ideas in a first work. See, e.g., Berkic v. Crichton, 761 F.2d 1289 (9th Cir. 1985). 


\section{A CRITIQUE OF XANADU'S MODELS}

\section{A. Concerning Its Model of Author Behavior}

One question raised by Nelson's proposal is whether authors, particularly good ones, will be willing to pay to publish their works in Xanadu. In the print world, some authors do pay to have their works published by "vanity presses," but this represents a small percentage of publications. There might be some authors who would pay to publish documents in Xanadu out of misplaced confidence in the value of their work, just as some authors now post messages of dubious information content to CompuServe or Internet newsgroups. Such authors would get negative feedback at the end of the first rental period when no royalties were credited to their account, and perhaps decide not to renew. However, some authors might decide not to renew their document rental space in Xanadu if no one linked to them during the first rental period, even though if they had stayed in the system, their documents would eventually have been discovered and made them a fortune. Still other authors might lack confidence in their work or might be too poor to afford the rental fee, which might cause them to withhold from the Xanadu system documents that would have been widely utilized if published there. Xanadu might benefit from a scheme by which authors could solicit sponsors willing to subsidize the inclusion of their works in Xanadu in exchange for some portion of the royalties.

Authors may not, in other words, behave in the way Xanadu's designer might expect them to behave. Authors may prefer the print world's system, which does not require them to pay directly for the privilege of being published. Authors may feel it is quite enough to have had to work hard to write the text in the first place. Some of the trick of authoring is writing something that publishers are willing to risk their capital to publish. A system that would make authors pay to get published may end up either deterring authorship or sending authors in search of another digital library/hypertext publishing system in which to place their work.

Nelson may also have underestimated how reluctant many authors may be about giving other people unlimited rights to make derivatives of their work. Although authors might have no objection to letting Xanadu users link to their documents, many may feel quite differently about allowing any Tom, Dick, or Susan to make new versions of their works. It will 
be little consolation to such authors that they might get royalties when the revised version is accessed by Xanadu users. Authors often regard their writings as expressions of their personalities. Any tampering with their texts may be viewed by such authors as a "mutilation" of the work, as objectionable as if someone had the effrontery to walk up to you and cut your hair without your permission. In many countries, authors are expressly granted "moral rights" in their intellectual products, one of which protects the integrity of the work. ${ }^{65}$ In the United States, the derivative work right of copyright owners protects authors' economic interests in controlling adaptations of their works, although sometimes unauthorized adaptations affect economic rights of authors as well as moral rights. ${ }^{66}$

Nelson, like many in the technical community, seems to have a very positive attitude about the acceptability of making use of someone else's work and building on it to create a better modified version. ${ }^{67}$ Nelson seems to have assumed that this attitude is more widespread in the authorial community than may, in fact, be true.

\section{B. Concerning Its Model of User Behavior and Incentives for Users To Become Authors}

The Xanadu intellectual property system also reflects a certain model of user behavior. Nelson proposes a number of incentives for people to make use of the Xanadu system for a wide variety of purposes, from research to entertainment to hobby to full-time occupation. Probably his most creative idea about user behavior is in contemplating the transformation of the digital library part of Xanadu into a hypertext publishing system, and incenting users to become system authors through linking and other derivative uses of documents in the system.

The royalty mechanism in Xanadu, however, may create some

65. See Martin A. Roeder, The Doctrine of Moral Right: A Study in the Law of Artists, Authors, \& Creators, 53 HARV. L. REV. 554 (1940); Roberta R. Kwall, Copyright and the Moral Right: Is an American Marriage Possible?, 38 VAND. L. REV. 1 (1985).

66. The United States relied on decisions such as Gilliam v. American Broadcasting Co., 538 F.2d 14 ( $2 \mathrm{~d} \mathrm{Cir.} \mathrm{1976)} \mathrm{(infringement} \mathrm{arose} \mathrm{from} \mathrm{unauthorized} \mathrm{editing} \mathrm{that} \mathrm{misrepresent-}$ ed author's work) to show that moral rights interests could be protected under U.S. law during the Berne Convention accession process. The only statutory provision conferring moral rights is 17 U.S.C. $\S 106 \mathrm{~A}$, which affects works of visual art.

67. See Allen Newell, Response: The Models Are Broken! The Models Are Broken!, 47 U. PIrT. L. REV. 1023, 1033-34 (1986) (cumulative revision practice of programmers yields improved programs). 
unfortunate, unintended incentives. The system would seem to give a special premium to those who are first to mention a particular topic in the Xanadu system, even if the first treatment of the topic were shallow or wrong. This may create incentives to rush documents into the system rather than to craft them to be deeper and more accurate. ${ }^{68}$ An example will illustrate one such problem.

Suppose a journalist attended the first conference of scientists concerning the just-formed Human Genome Initiative ("HGI"), that he was an avid Xanadu user, and that at the first break in the conference schedule, the journalist authored a document for Xanadu describing in a shallow but intelligible way what HGI was about. By virtue of being the first to mention HGI in Xanadu, this journalist's entry might be, for a time at least, the most frequently linked to source on HGI in Xanadu, which would make him the most compensated author on the topic.

A naive user of Xanadu, when faced with a decision whether to access the journalist's HGI description or a later much deeper one by a scientist who was a founder of the HGI, might see that the first had been linked to a thousand times, whereas the scientist's document had been linked to only five times in the time it was on the system. This might cause the user to choose the more frequently cited source over the better but less frequently cited source, again causing more royalties to flow into the journalist's account, and incenting rushed documents over considered documents in the system. In the print world, the shallow first treatment on a topic will tend to be ignored by later authors, but in Xanadu, the first document to mention a subject might always be called up on a user search, and not until the user reads the shallow document (and hence pays the author royalties on it) will the user know to ignore it. Even creating a derivative document advising users to ignore the underlying document will result in royalties to the author of the underlying document.

Suppose further that the journalist's Xanadu document on HGI contained some errors. Other Xanadu users might well notice the errors, and make derivative documents containing the needed corrections. Although this would correct the error, an inadvertent result of the scenario would be that the journalist might make a lot of money from

68. This phenomenon is well known in conventional publication media, of course. A visit to a bookstore or grocery store uncovers scores of slipshod books that report on the latest fad, war, movie, or entertainment personality. But Xanadu would be likely to increase the odds that first-in authors would be rewarded because it does not allow readers to scan the work while waiting in line at the cash register in order to discover how shallow it really is. 
putting out an erroneous document, for every time someone linked to his document or created a revised version of it, the journalist would share in the revenues. The more and more noticeable the errors in the document, the more Xanadu users would be likely to notice the errors, to link to the journalist's document, and/or to revise it, which once again would generate more revenues for the journalist. This would seem to over-reward the journalist for rushing to get his document on HGI into the Xanadu system and not to deter entry of erroneous information.

Usage-based systems, such as Xanadu, may also have the disadvantage, at least for price-sensitive users, of making those with the most curiosity and tenacity in research pay the highest cost. They are the ones who will presumably use Xanadu for longer periods of time. One might argue that this is fair because those who use the system the most are those who pay most. But some may conceive the issue differently, and think it one of the great virtues of the library systems of the print world that scholars do not have to pay more than casual users for access to the library. Society has an interest in encouraging deep scholarship. By not making scholars or other deep users pay more for their use of the library, the print world encourages scholarship. Digital library and hypertext publishing systems may also need to find ways to encourage good scholarship and curiosity without making it prohibitively expensive. ${ }^{69}$

But a more serious problem perhaps than this may be figuring out how to motivate users to be persistent and creative in their use of the Xanadu system. When people use traditional libraries, they can walk around and browse until they find something to interest them. In Xanadu, the clock will be ticking and the price will be rising as one browses. Also, digital libraries, because of their invisibility to the user, may be too abstract to be enjoyably browsable. Once again, Nelson may have mistakenly modeled the Xanadu user in terms of his own persistence and creativity, which others may not share.

\section{Questions About Pricing Incentives}

Perhaps the single most questionable element of the Xanadu intellectu-

69. For this reason, the pricing model for digital libraries may well be on a subscription basis by institution. See INI REPORT, supra note 8 . Such a pricing model would put unaffiliated scholars or small institutions at a considerable disadvantage. It is far from clear that public libraries will be able to provide the same kind of access to a wide variety of published works in digital form as they have for printed works. 
al property scheme, in terms of economic incentives, is pricing. If one looks at the universe of copyrighted works in the print-dominated world, one immediately observes that copies are priced according, more or less, to what the publisher/distributor and author/creator think the market will bear for the number of copies that might reasonably be sold or licensed. Xanadu posits a flat fee for Xanadu connect time and a fixed royalty for authors based on per-byte delivery for usage of their documents. This is like mandating that all books are to be priced according to the number of pages they contain and all pages must be priced at the same amount. The CompuServe example seems to suggest that differential pricing of information is necessary to encourage the development of specialized markets. Unless Xanadu were the world's only digital library and hypertext publishing system, which remains Nelson's vision but which is unlikely, Xanadu will lack the negotiating power to compel authors to accept fixed pricing per byte of their information. ${ }^{70}$

People who own copyrights in very valuable intellectual properties simply will not use a system that does not let them make market-based pricing decisions. The only options authors of very valuable intellectual properties would have in the world Nelson envisions is to put the work in Xanadu as an encrypted private document and contract with users for access to the document, or to withhold the document from Xanadu altogether. While encryption might allow market pricing to occur, Xanadu does not facilitate these transactions. They must be dealt with by private negotiations between the parties, but if Xanadu does not facilitate the transactions, it is difficult to see how they can occur. The transaction costs of individual negotiations that would have to occur without Xanadu's help in order to access an encrypted document in Xanadu might be inordinately high. ${ }^{71}$

Another question we have about Nelson's Xanadu economic model is whether it overemphasizes author and user incentives and underemphasizes the need for some of the value-added services that publishers in the print world provide, particularly as to the promotion of sales of the work,

70. If Xanadu were the only means for authors to publish their works, it would have what economists call monopsony power, power over price and other terms of a bargain due to being the only buyer with whom many sellers can deal, a situation that might give rise to substantial antitrust concerns.

71. Similar complaints about transaction costs for licensing of rights for digital media are motivating the development of new copyright collectives for electronic works modeled after ASCAP and BMI for the music industry. See Nathan Benn, Copyright Collectives and Reproduction Rights in Electronic Media, 5 NEW MEDIA NEws 21, 21-23 (1991). 
whether by advertising or otherwise. Nelson wants people to use Xanadu, for that's how the system makes money. But Xanadu is indifferent to what they use. The lack of a promotional system for works in Xanadu may lead to underutilization of the system, which in turn may affect its commercial viability.

\section{CONCLUSION}

Whether digital library or hypertext publishing systems can be made commercially viable will depend on how they deal with intellectual property rights issues. The traditional copyright model will require adjustments in order to facilitate these new kinds of institutions. Ted Nelson offers one model of how such adjustments might be made. While Nelson's intellectual property scheme for the Xanadu system is bold and innovative, there are a number of respects in which his system can be questioned. The most uncertain aspects of the Xanadu system are the accuracy of the Xanadu model of author and user behavior, and the adequacy of financial incentives for authors to put their most valuable copyrighted works in the Xanadu system.

A generation of exposure to tape recorders and VCRs-and a raft of new digital technologies for scanning, frame grabbing, and sampling-are making it harder to predict how people will understand and relate to intellectual property. ${ }^{2}$ What is legal, and what is merely technically possible to copy? What constitutes "fair use" of copyrighted works in digital form? ${ }^{73}$ Laws that were suited for traditional kinds of copyrighted works no longer seem to fit.

More work is needed to develop new models of author and user behavior and the economics that will yield the right level of incentives for creation of digital library and hypertext publishing systems. The law can be made to conform to these new models, but only after we figure out what the right ones are.

72. See OTA REPORT, supra note 6, at 190-213 (Public thinks private noncommercial copying is not infringement.).

73. The first case in which fair use was successfully invoked in the digital domain was Lewis Galoob Toys v. Nintendo of Am., 964 F.2d 965 (9th Cir. 1992). Nintendo had alleged that Galoob's Game Genie, which permits users to change certain characteristics of the play of Nintendo games, infringed because it permitted unauthorized creation of derivative works, namely, the altered play of the game. The Court of Appeals expressed some doubt that a derivative work had been created, but ruled that even if it had, the fair use defense was available to Galoob. 
HeinOnline -- 6 Harv. J. L. \& Tech. 262 1992-1993 